\title{
The reproductive biology of the scleractinian coral Plesiastrea versipora in Sydney Harbour, Australia
}

\author{
Alisha Madsen ${ }^{1}$, Joshua S. Madin ${ }^{1}$, Chung-Hong Tan ${ }^{2}$, Andrew H. Baird ${ }^{2, *}$ \\ ${ }^{1}$ Department of Biological Sciences, Macquarie University, Sydney, New South Wales 2109, Australia \\ ${ }^{2}$ ARC Centre of Excellence for Coral Reef Studies, James Cook University, Townsville, Queensland 4811, Australia
}

\begin{abstract}
The scleractinian coral Plesiastrea versipora occurs throughout most of the IndoPacific; however, the species is only abundant in temperate regions, including Sydney Harbour, in New South Wales, Australia, where it can be the dominant sessile organism over small spatial scales. Population genetics indicates that the Sydney Harbour population is highly isolated, suggesting long-term persistence will depend upon on the local production of recruits. To determine the potential role of sexual reproduction in population persistence, we examined a number of features of the reproductive biology of $P$. versipora for the first time, including the sexual system, the length of the gametogenetic cycles and size-specific fecundity. $P$. versipora was gonochoric, supporting recent molecular work removing the species from the Family Merulinidae, in which the species are exclusively hermaphroditic. The oogenic cycle was between 13 and 14 mo and the spermatogenetic cycle between 7 and $8 \mathrm{mo}$, with broadcast spawning inferred to occur in either January or February. Colony sex was strongly influenced by colony size: the probability of being male increased with colony area. The longer oogenic cycle suggests that females are investing energy in reproduction rather than growth, and consequently, males are on average larger for a given age. Alternatively, colonies may change sex from female to male as they grow. In contrast, per polyp fecundity did not vary with colony size. We conclude that the Sydney Harbour population is reproductively active and therefore has the potential to maintain current levels of abundance even without an external supply of propagules.
\end{abstract}

KEY WORDS: Coral reefs $\cdot$ Reproduction $\cdot$ Sex change $\cdot$ Tropicalisation $\cdot$ Climate change $\cdot$ Larval ecology

\section{INTRODUCTION}

Of the over 1500 scleractinian coral species (Cairns 1999), reproductive traits, such as sexual system and mode of larval development, are known for approximately 450 species (Baird et al. 2009b). However, nearly all of these records are from the tropics, and consequently, very little is known about the reproductive biology of corals in temperate locations. Many coral species have very large range sizes, with some extending over $60^{\circ}$ of latitude. Consequently, these species may be ideal organisms with which to test evolutionary hypotheses, such as the role of environment in determining life history traits.

\footnotetext{
*Corresponding author: andrew.baird@jcu.edu.au
}

On the east Australian coastline, a number of subtropical coral assemblages occur to the south of the Great Barrier Reef (Veron 1993). The Solitary Islands contain the last diverse coral assemblages on the east Australian coast with $\sim 115$ scleractinian species (Harriott et al. 1994), and Lord Howe Island has the southernmost fringing reef in the Pacific with $\sim 65$ species in 33 genera (Veron 1993). High latitude corals experience lower mean annual sea surface temperatures (SST) and lower aragonite saturation states, both of which are likely to result in reduced growth and fecundity (Kleypas et al. 1999, Harriott \& Banks 2002), potentially making these populations reliant on recolonization by larvae from tropical

() The authors 2014. Open Access under Creative Commons by Attribution Licence. Use, distribution and reproduction are unrestricted. Authors and original publication must be credited. 
waters (Veron \& Done 1979). However, corals at high latitudes do reproduce (see summary in Fellegara et al. 2013). For example, high latitude coral communities in Japan are reproductively active and are key contributors to maintenance of local populations (van Woesik 1995, Nozawa et al. 2006).

Important features of coral reproductive biology likely to influence the evolution and ecology of species include the sexual system, the mode of larval development and mode of larval nutrition (Baird et al. 2009b). Sexual systems in scleractinian corals generally fall into one of 2 categories (Kerr et al. 2011). Individual colonies are either hermaphrodites, in which each polyp contains both male and female gametes when mature, or gonochores, in which every polyp in a colony contains either male or female gametes. Sexuality is also a highly conserved and therefore a good indication of evolutionary relationship (Baird et al. 2009b). Similarly, there are only 2 modes of larval development in corals (Kerr et al. 2011). Fertilization is either internal with larvae brooded within the polyps, or fertilization is external following the broadcast spawning of gametes (Baird et al. 2009b, Harrison 2011). The mode of larval nutrition is either autotrophic, where oocytes are inoculated with algal symbionts from which the developing larva can derive nutrition (Richmond 1987), or lecithotrophic, where oocytes are not inoculated with symbionts, and consequently, larval development depends on maternal provisioning of the oocyte (Baird et al. 2009b).

Plesiastrea versipora is a hermatypic scleractinian coral with a very large range size, extending from Kyushu, Japan, in the northern hemisphere to South Australia, in the southern hemisphere and from the Red Sea in the west to French Polynesia in the east (Veron 2000). P. versipora has traditionally been included in the Family Faviidae (Veron 2000). However, recent molecular work indicates that $P$, versipora should be included in a separate previously unrecognized clade (Benzoni et al. 2011, Huang 2012). P. versipora is rarely abundant in the tropics, if it occurs at all; however, it often dominates the benthos in temperate regions (Veron 2000). For example, a large population of $P$. versipora occurs in Sydney Harbour at $33^{\circ} \mathrm{S}$ (Fig. 1). The population genetics of $P$. versipora along the east coast of Australia suggests that the Sydney Harbour population is highly isolated and originated from a recent range expansion
(Rodriguez-Lanetty \& Hoegh-Guldberg 2002). Very little is known about the reproductive biology of this widespread species.

The aim of this project was to examine the reproductive biology of Plesiastrea versipora in Sydney Harbour. The following specific reproductive traits were investigated: (1) sexual system, (2) sex ratio, (3) mode of larval development, (4) length of the gametogenic cycles, (5) spawning time, (6) fecundity as a function of colony size, and (7) sex as a function of colony size.

\section{MATERIALS AND METHODS}

Sydney Harbour $\left(33^{\circ} \mathrm{S}, 151^{\circ} \mathrm{E}\right)$ is an inlet of the South Pacific Ocean. A substantial population of Plesiastrea versipora occurs adjacent to Fairlight Pool, in the northern part of the Harbour, at 3 to $7 \mathrm{~m}$ depth on staggered rock platforms (Fig. 1). The reproductive biology of $P$. versipora was investigated in most months for 14 mo between January 2011 and March 2012. Field trips were conducted 1 to $2 \mathrm{~d}$ prior to the full moon in order to capture gametes prior to spawning, which for tropical reef corals in Australia typically occurs following the full moon (Harrison et al. 1984). Prior to tissue sampling, several high resolution digital photographs were taken of whole, standalone, and healthy colonies, each of which included a $10 \mathrm{~cm}^{2}$ scale reference plate for estimating colony area. Photographs were corrected for barrel distortion, colonies were digitally outlined, and planar

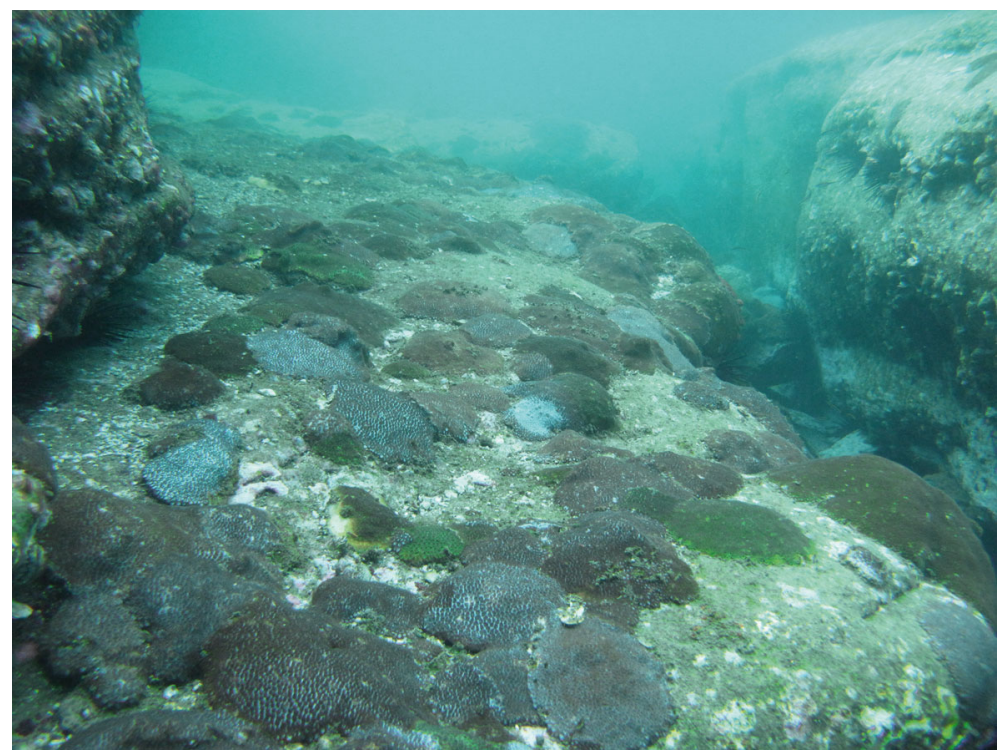

Fig. 1. High densities of Plesiastrea versipora at $6 \mathrm{~m}$ depth, off Fairlight Pool, in Sydney Harbour, Australia 
areas were estimated using ImageJ. Coral fragments of $\sim 4 \mathrm{~cm}^{2}$ were sampled from the centre of 10 haphazardly selected colonies using a hammer and chisel or a $2 \mathrm{~cm}^{2}$ steel punch. Fragments contained between 10 and 20 polyps. Gamete maturity is generally consistent for all polyps within a colony (Baird et al. 2011). Therefore, 1 fragment per colony was deemed adequate for capturing the state of maturity of the colony.

Fragments were fixed in $10 \%$ buffered formaldehyde for $24 \mathrm{~h}$. Following fixation samples were rinsed in distilled water and placed in $70 \%$ ethanol. For analysis fragments were then decalcified in $10 \%$ formic acid. Half of each fragment was dissected to estimate per polyp fecundity, while the other half was placed in a perforated cassette and stored in $70 \%$ ethanol and the processed for histology.

Six polyps were selected haphazardly from each fragment for dissection. Each polyp was initially sexed on the basis of the shape and texture of the gametes. Oocytes were circular or elliptical in shape, a cream colour with a clear outline and solid to the touch. In contrast, spermaries were elongate amorphorous white bodies. This initial determination of the sex of the polyps was confirmed by histology, and on only one occasion was a male incorrectly classified as a female. For female polyps the number of oocytes was counted, and then the size of 10 randomly chosen oocytes was measured from high resolution digital images. AnalySIS FIVE image analysis software calibrated with the stereo microscope automatically calculated average oocyte size in microns based on scaled photographs.

Tissue samples set aside for histology were processed following Baird et al. (2011). Samples were first dehydrated in an alcohol series, cleared using Histo-Clear (National Diagnostics), and then embedded in paraffin wax. Samples were then oriented to allow both transverse and longitudinal sectioning if possible and cut with a microtone at $7 \mu \mathrm{m}$ thickness, and 3 to 4 sections $\sim 50 \mu \mathrm{m}$ apart were mounted onto slides. Slides were then taken to water and stained using Mayer's haematoxylin and Young's eosinerythrosine. The haematoxylin stains nuclei blue, and the eosin-erythrosin stains cytoplasmic elements various shades of red. Slides were then covered with haematoxylin for $8 \mathrm{~min}$, rinsed and then covered with Scott's tap water substitute for $30 \mathrm{~s}$, rinsed again then covered with eosin-erythrosin for $3 \mathrm{~min}$, rinsed and then dehydrated. Cover slips were mounted in DPX (di-n-butyle phthalate in xylene). Gamete maturity was determined using criteria modified from VargasÁngel et al. (2006) and Baird et al. (2011).
To examine the relationship between SST and average oocyte size throughout the sampling period, temperature data were collected using temperature loggers deployed at Little Manly within $2 \mathrm{~km}$ of the study site at Fairlight Pool.

In order to determine the time of spawning, 6 colonies were collected off Fairlight Pool and maintained in aquaria at Macquarie University, Sydney. Aquaria were situated indoors under fluorescent lights on a $12 \mathrm{~h}$ light:12 h dark schedule. Aquaria were not flow-through so water was changed twice daily. The colonies were maintained under these conditions for $3 \mathrm{wk}$. Aquaria were checked twice daily for the presence of gametes in the water column.

A Pearson's chi-squared was used to determine if the sex ratio was significantly different to half females/half males using the function chi.sq.test in R. One-way ANOVA was used to determine if average oocyte geometric diameter and average per polyp fecundity differed among sampling months. Tukey's multiple comparisons of means tests identified which months, if any, differed in mean oocyte size and per polyp fecundity. Regressions were used to determine the strength and significance of relationships between log-transformed colony size and mature oocyte number and mature oocyte diameter. For these regressions, only data from January 2012 were used, because histology suggested that almost all colonies were mature in this month $(\mathrm{n}=30)$. Logistic regression was used to test for an association between log-transformed colony size and sex using the glm function with binomial family in $\mathrm{R}$.

\section{RESULTS}

\section{Sexuality, mode of larval development and sex ratio}

Plesiastrea versipora at Fairlight Pool is a gonochore. All polyps examined both by dissections and histology contained gametes of only one sex, and all polyps within a colony were of the same sex. P. versipora is also highly likely to be a broadcast spawner. Planulae were never observed in histological sections. In addition, there was a large reduction in per polyp fecundity between January and February in 2012. A total of 140 colonies were sampled in the study: 51 were females, 55 males and a further 34 colonies did not contain gametes. This sex ratio was not significantly different from 1:1 $\left(\chi^{2}=0.151 ; \mathrm{df}=1\right.$; $\mathrm{p}=0.698)$. 


\section{Gametogenetic cycles and size of oocytes}

Stage I oocytes were only evident in December in $50 \%$ of the female colonies, indicating that oogenesis commenced in this month (Fig. 2). Interestingly, Stage I oocytes were often observed in the same mesentery as Stage IV oocytes, suggesting that the oogenic cycle is longer than 12 mo (Fig 2A). Following the initiation of oogenesis in December, the proportion of colonies with Stage II (Fig. 2B) and III oocytes (Fig. 2C) increased until November, when $100 \%$ of colonies had mature oocytes (Fig. 2D \& Fig. 3). Mature oocytes continued to be observed in 30 to $50 \%$ of colonies until February (Fig. 3). Consequently, the

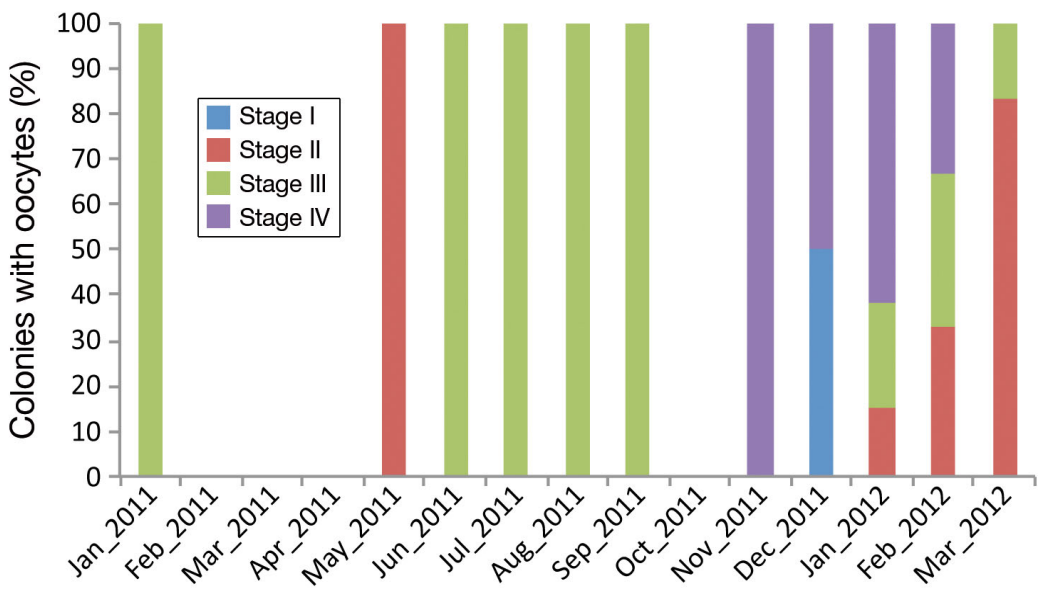

Fig. 3. Proportion of Plesiastrea versipora colonies with oocytes in various stages of maturity as determined by histology between January 2011 and March 2012. No samples were collected in either March or October 2011. Sample sizes as follows: Jan $2011=4$; May $2011=3$; Jun $2011=2$; Jul $2011=2$; Aug 2011 = 3; Sep 2011 = 5; Nov 2011 = 1; Dec 2011 = 2; Jan 2012 = 13; Feb 2012 = 3; Mar 2012 = 6; only males were sampled in February 2011 and no males were processed for histology in April 2011
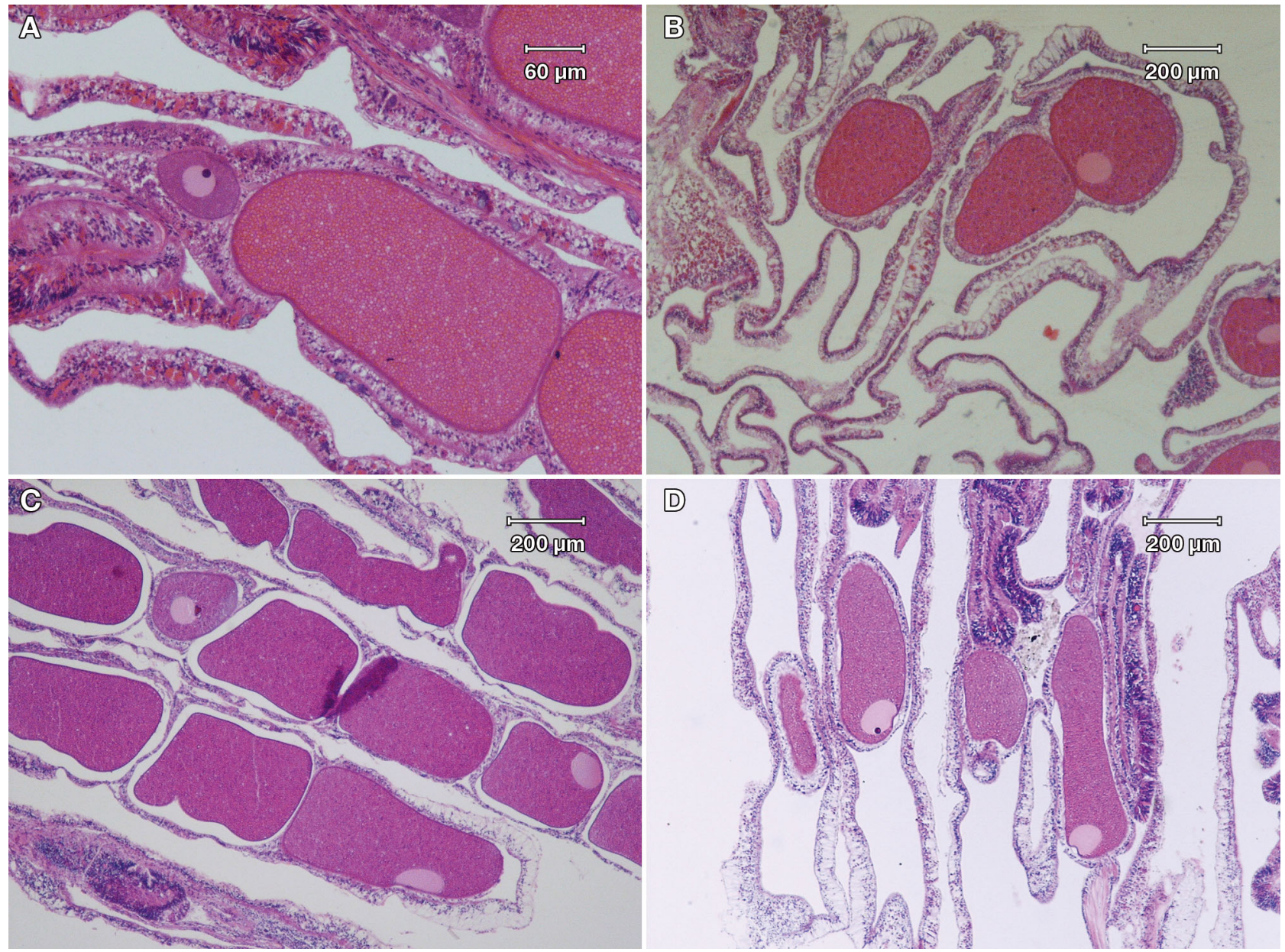

Fig. 2. Oogenesis in Plesiastrea versipora. (A) Stage I and Stage IV oocytes in the same polyp indicating 2 overlapping oogeneic cycles; (B) Stage II oocytes; (C) Stage III oocytes; (D) Stage IV oocytes 
oogeneic cycle was estimated to last between 11 and $14 \mathrm{mo}$, commencing in December and lasting until November the following year at the earliest or February the year after that at the latest. These changes in the stage of maturity of oocytes were supported by changes in oocyte diameter, which varied significantly between months (ANOVA: $\mathrm{df}=12, F$ $=39.9, \mathrm{p}<0.001$; Fig. 4). In April 2011, when oocytes were first dissected, the mean diameter was $235 \pm$ 14.7 SE (Fig. 4). Oocytes grew rapidly between April and June, increasing in mean diameter by over $50 \%$ to $\sim 401 \pm 14.8 \mathrm{SE}$ (Fig. 4). Between June and November there

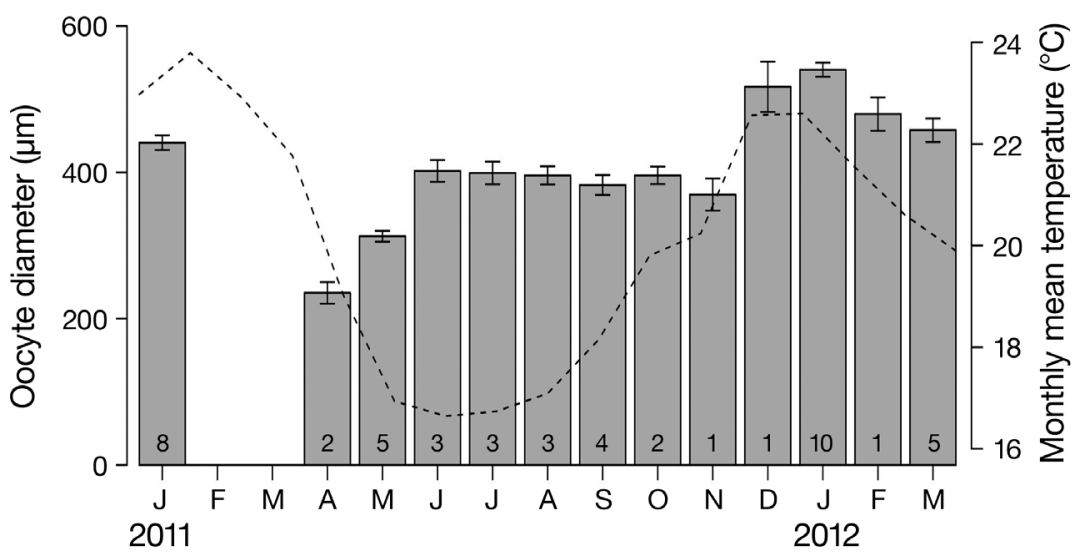

Fig. 4. Oocyte size (geometric mean maximum diameter $\pm 1 \mathrm{SE}$ ) in Plesiastrea versipora between January 2011 and March 2012. No samples were collected in March 2011, and only males were sampled in February 2011. Temperature data (dashed line) are average daily sea temperatures from data loggers at $2 \mathrm{~m}$ depth at Little Manly, less than $2 \mathrm{~km}$ from the study site at Fairlight Pool, Sydney Harbour, Australia

was no significant change in ooctye

diameter, generally coinciding with the coldest months of the year (Fig. 4). Between November and December there was a significant jump in oocytes diameter to $517 \pm 34.3 \mathrm{SE}$ after which the mean oocyte size decreased slightly until March (Fig. 4).

Stage I spermaries (Fig. 5A) were first observed in July 2011 (Fig. 6). Following this, the proportion of colonies with Stage II (Fig. 5B) and III (Fig. 5C) spermaries increased until January 2012, when $100 \%$ of colonies had Stage IV gametes (Fig. 5D \& Fig. 6). Consequently, the spermatogenetic cycle was between 7 and 8 mo long, 3 to 7 mo shorter than the oogenic cycle.

\section{Colony fecundity and spawning time}

Average per polyp fecundity varied throughout the year (ANOVA df $=12, F=15.01, p=<0.001$; Fig. 7 ). Polyp fecundity was high in January 2011 (Fig. 7). In February 2011, all colonies sampled were male, suggesting that most females released gametes following the full moon in January 2011 (Fig. 7). Per polyp fecundity was next estimated in April 2011 at $28.3 \pm$ 1.11 SE (Fig. 7) after which there was little change in fecundity until December 2011, coinciding with the initiation of a new gametogenetic cycle (see 'Gametogenetic cycles and size of oocytes' above). Fecundity peaked in February 2012 at $80.7 \pm 13.32 \mathrm{SE}$ oocytes per polyp (Fig. 7). Between February and March 2012 fecundity dropped dramatically to $15.8 \pm$ 2.88 SE (Fig. 7), suggesting that 20 mature oocytes per polyp were released following the full moon in February 2012.

\section{Reproductive traits as a function of colony size}

The smallest colony sampled had an area of $5.5 \mathrm{~cm}^{2}$. The smallest colony with gametes was a female with an area of $21.6 \mathrm{~cm}^{2}$. Above this colony size most colonies contained gametes. Mature per polyp fecundity was independent of colony area $\left(\mathrm{p}=0.062, \mathrm{r}^{2}=\right.$ 0.058; Fig. 8). While mature oocyte size increased slightly with increasing colony area $\left(\mathrm{p}=0.041, \mathrm{r}^{2}=\right.$ 0.054 ; Fig. 9), area only explained $5.4 \%$ of the variation in per polyp fecundity. Larger colonies, in particular those greater than $400 \mathrm{~cm}^{2}$, were more likely to be male than female $(n=104, p<0.001$; Fig. 10).

\section{DISCUSSION}

Plesiastrea versipora is gonochoric, with horizontal transmission of symbionts, and is most likely a broadcast spawner. A high proportion (75\%) of colonies in Sydney Harbour were breeding, indicating that high latitude and low temperature are no impediment to reproduction in this cosmopolitan species. The duration of the oogenic cycle was between 11 and $14 \mathrm{mo}$, and the spermatogenic cycle between 7 and 8 mo. Spawning most likely occurred following the full moon in January in 2011 and February in 2012, although the presence of mature oocytes between November and February suggests that some eggs may also be released in these months. Colony size was weakly associated with oocyte size but not with per polyp fecundity. In contrast, colony size was strongly associated with sex, with all colonies greater than $400 \mathrm{~cm}^{2}$ being male. 

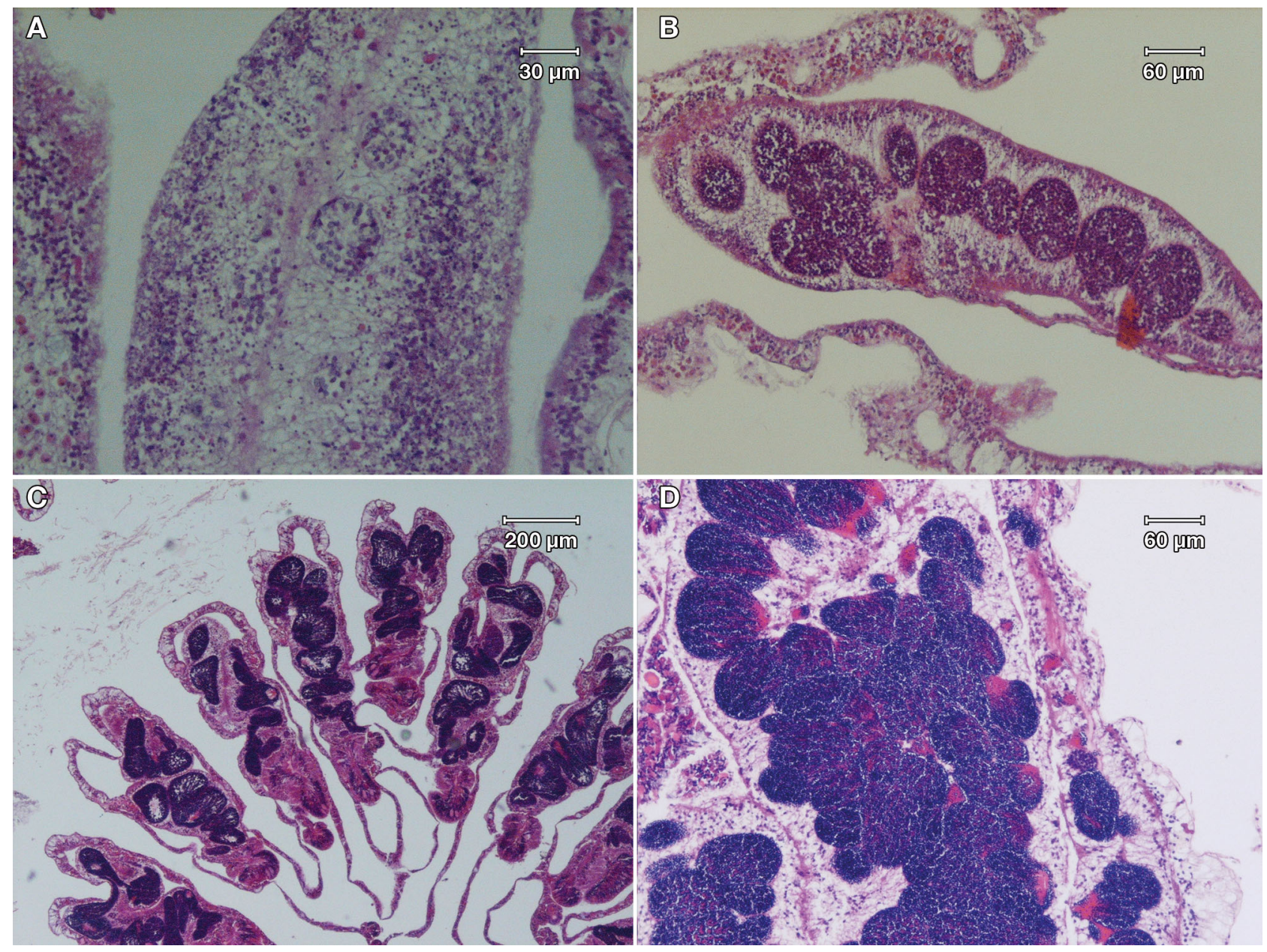

Fig. 5. Spermatogenesis in Plesiastrea versipora. (A) Stage I spermaries; (B) Stage II spermaries; (C) Stage III spermaries; (D) Stage IV spermaries

Sexuality in corals is a highly conserved trait (Harrison 1985, Kerr et al. 2011), with very few of the recently defined molecular clades containing species with differing sexuality (Baird et al. 2009b, Harrison 2011). This suggests that sexuality is a good character for taxonomic studies. The fact that Plesiastrea versipora is gonochoric strongly supports the recent removal of this species from the exclusively hermaphroditic family Merulinidae into the new Clade XIV consisting only of gonochores (Huang 2012).

In contrast to sexuality, the mode of larval development is 4 times more likely to evolve between character states than sexuality (Kerr et al. 2011), and therefore, this feature of reproductive biology is less useful as an indicator of evolutionary relationships. Nonetheless, all 3 other species for which the mode of larval development is known in Clade XIV are broadcast spawners (Baird et al. 2009b), indicating that spawning is the most likely mode of larval devel- opment in Plesiastrea versipora. Furthermore, P. versipora releases gametes into the water column in Taiwan (Dai et al. 1992) and on the Great Barrier Reef (Willis et al. 1985).

Symbiodinium was never observed in mature oocytes (Fig. 2), indicating that the transmission of these obligate algal symbionts in Plesiastrea versipora is horizontal (i.e. each generation must acquire a new complement of symbionts from the environment). Horizontal transmission is likely to be adaptive for species with a wide latitudinal range size, allowing larvae to select symbionts most suited to local conditions following dispersal (Baird et al. 2007, Cumbo et al. 2013). In support of this hypothesis, $P$. versipora hosts Symbiodinium from Clade C in subtropical and tropical latitudes on the east Australian coast, whereas at temperate locations, including Sydney Harbour, it hosts Clade B (Rodriguez-Lanetty et al. 2001). 


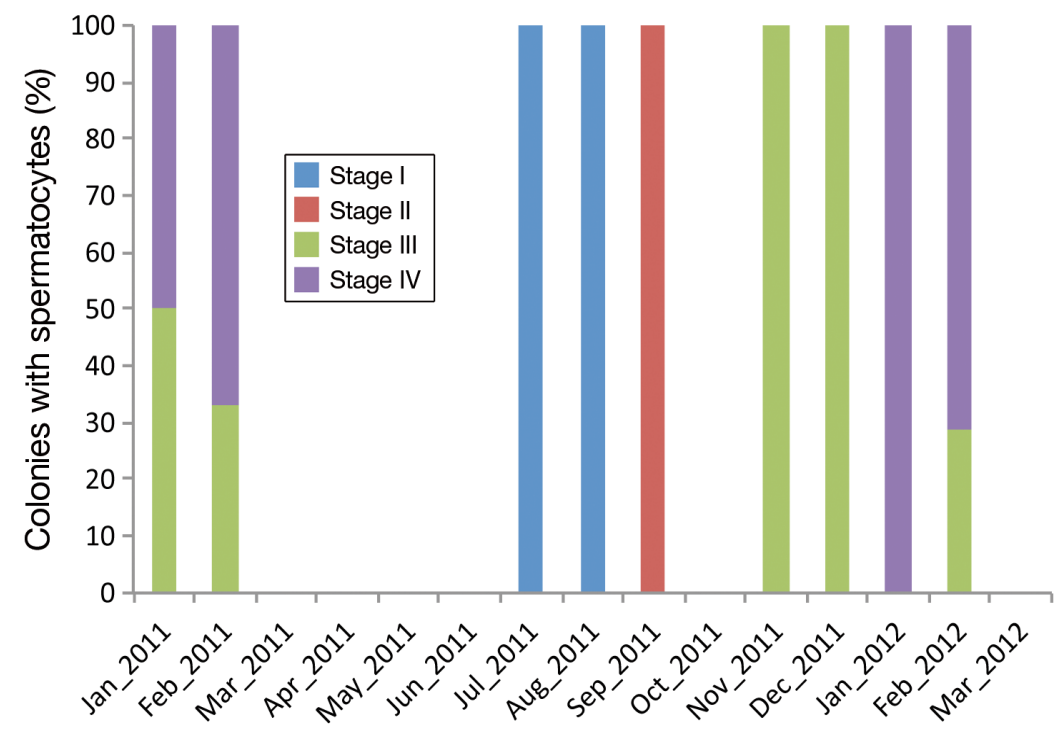

Fig. 6. Proportion of Plesiastrea versipora colonies with spermatocytes in various stages of maturity as determined by histology between January 2011 and March 2012. No samples were collected in March and October 2011, and there were no male colonies detected in the dissections in April, May and June 2011 and March 2012. Sample sizes as follows: Jan $2011=2 ;$ Feb $2011=$ 3; Jul 2011 = 1; Aug $2011=2 ;$ Sep $2011=2 ;$ Nov $2011=2 ;$ Dec $2011=5$; Jan $2012=14 ;$ Feb $2012=6$

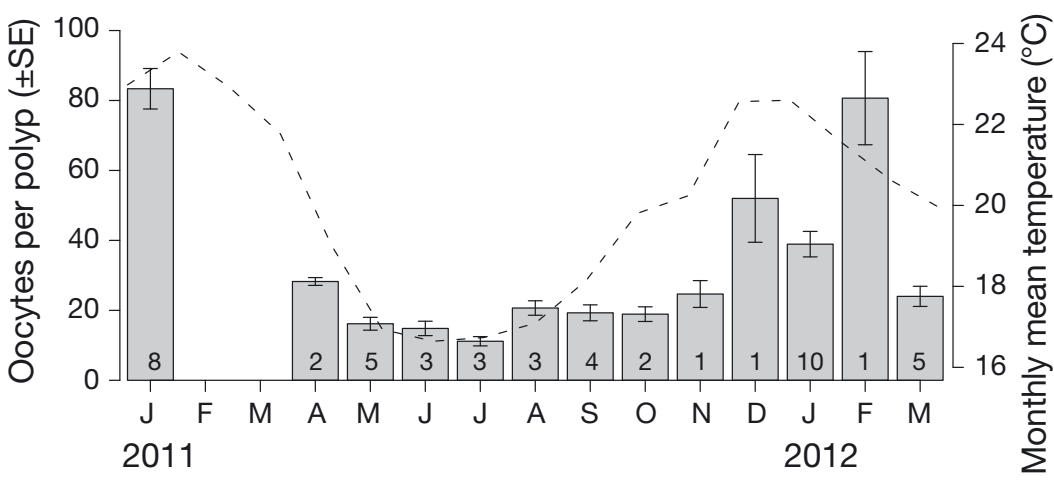

Fig. 7. Fecundity (no. of oocytes per polyp) in Plesiastrea versipora (mean \pm 1 SE) between January 2011 and March 2012. Only males were collected in February 2011, and no collection occurred in March 2011. Dashed line shows monthly mean temperature. Sample sizes given in bars

high latitudes are likely to limit the energy available to invest in reproduction in photosynthetic organisms, such as corals (van Woesik et al. 2006). Similarly, oogenesis in Alveopora japonica at high latitudes in Japan was 8 mo longer than that of a con-generic species $A$. daedalea in the Red Sea (Harii et al. 2001). In addition, the solitary gonochoric brooding coral Leptopsammia pruvoti in temperate waters of the Mediterranean has an oogenic cycle of 24 mo and a spermatogenic cycle of $12 \mathrm{mo}$, further suggesting that gametes take longer to reach maturity in temperate regions (Goffredo et al. 2006). Temperature also appeared to influence various stages in the oogenic cycle. For example, the initiation of oogenesis and the final maturation of oocytes coincided with rapid rises in water temperature in December (Fig. 4), providing further support for the suggestion that temperature has a primary role in gamete development (Harii et al. 2001, Nozawa et al. 2006, van Woesik et al. 2006).

Although spawning was not observed directly, reductions in fecundity between January and February in 2011 and between February and March in 2012 suggest that most colonies spawned oocytes some time after the full moon in January in 2011 and February 2012. However, histological examination indicated mature oocytes in at least some colonies from November to February (Fig. 3). Mature oocytes are usually released around the full moon following maturation (Harrison et al. 1984), so it is

Gametogenic cycles in Plesiastrea versipora were longer than in most tropical broadcast spawning species that usually have a single annual oogenic cycle of between 5 and 9 mo and a spermatogenic cycle of between 3 and 5 mo (Harrison \& Wallace 1990). An extended period of gametogenesis is most probably due to the lower annual average mean sea temperatures at high latitude because the rates of most biological process are positively correlated with temperature (Crossins \& Bowler 1987). In addition, low levels of photosynthetically available radiation at possible that some colonies released some oocytes in these months. This split spawning phenomenon within populations is very common even in the tropics, where spawning is generally considered to be highly synchronous within populations (Baird et al. 2002). Alternatively, Plesiastrea versipora colonies may retain mature oocytes for an extended period, similar to some corals in the Persian Gulf (Bauman et al. 2011). Spawning of $P$. versipora occurs at a similar time to major spawning episodes in Moreton Bay (Fellegara et al. 2013), Lord Howe Island (Harrison 


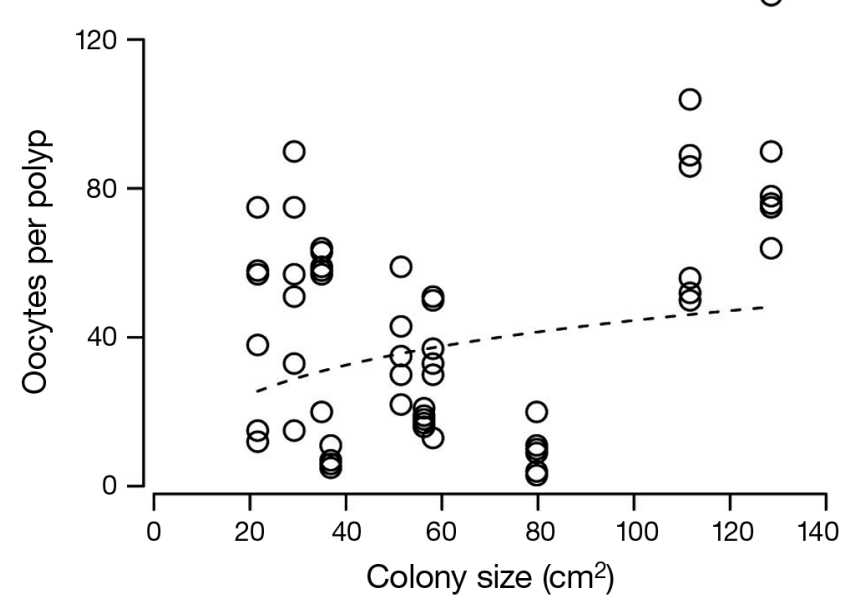

Fig. 8. Per polyp fecundity in Plesiastrea versipora as a function of mature colony size in January 2012. Dashed line is the line of best fit

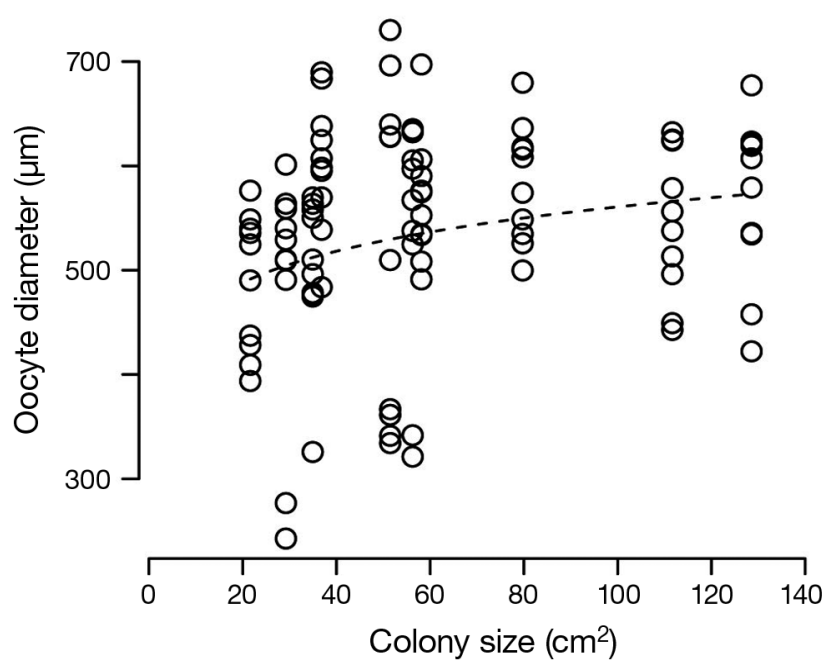

Fig. 9. Mature oocyte diameter in Plesiastrea versipora as a function of colony size in January 2012. Dashed line is the line of best fit

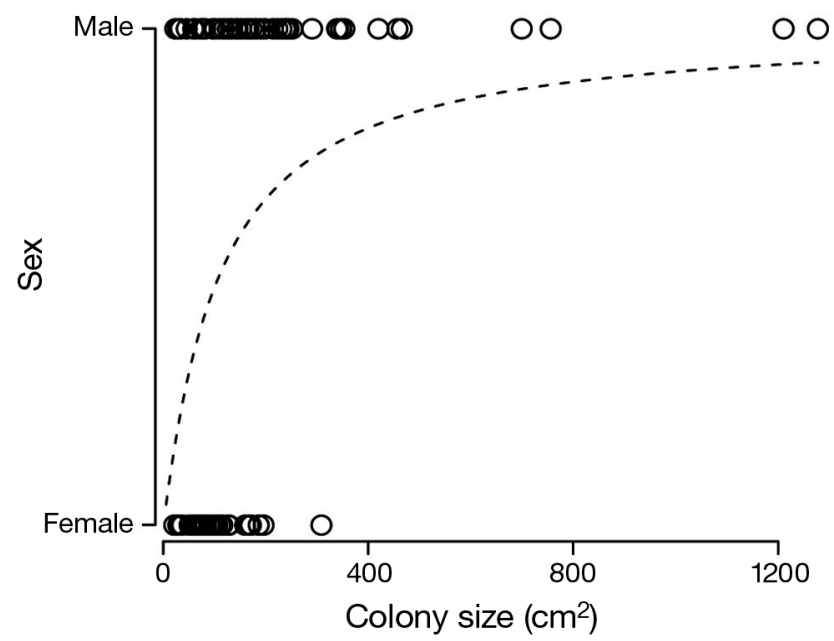

Fig. 10. Sex as a function of colony size in Plesiastrea versipora. Dashed line is the line of best fit
2008) and the Solitary Islands (Wilson \& Harrison 2003) but 2 mo later than the peak in spawning activity on the Great Barrier Reef (Harrison et al. 1984). A similar difference in the timing of spawning with increasing latitude also occurs in the Japanese Archipelago (Baird et al. 2009a). The reproductive activity in summer in $P$. versipora is consistent with the idea that broadcast spawning species generally have short annual spawning periods in the warmer months of the year (Harrison et al. 1984).

Per polyp fecundity and oocyte diameter were largely independent of colony size (Figs. $8 \& 9$ ). Thus, colony fecundity was a simple function of the number of polyps, i.e. fecundity increases with colony size. This appears to be the typical pattern in scleractinian corals. For example, in 7 species of hermatypic corals at a high latitude community in Japan fecundity increased with colony size (Nozawa et al. 2006). Similarly, per polyp fecundity was independent of colony size in 6 common corals on Lizard Island on the Great Barrier Reef (Hall \& Hughes 1996).

Sex was strongly associated with colony size. The probability of being a male increased with colony size, such that all colonies were male when colony area was greater than $400 \mathrm{~cm}^{2}$ (Fig. 10). There are 3 possible explanations for this: (1) females are changing to males at some critical size threshold, (2) females are investing more in reproduction at the cost of investing in growth, or (3) female mortality increases at a critical size or is generally higher. Bidirectional sex change occurs in the solitary coral Ctenactis echinata (Loya \& Sakai 2008); however, the cause of these sex changes has yet to be established. Repeated sampling of individuals through time will be required to determine why sexuality is associated with colony size in Plesiastrea versipora.

In conclusion, the Plesiastrea versipora population in Sydney Harbour is reproductively active and therefore has the potential to maintain current levels of abundance in the absence of external input of propagules. Reproductive traits, in particular sexuality and the putative mode of larval development, were consistent with the recent taxonomic revisions placing the species in a new clade (Huang 2012). The estimated time of spawning is consistent with other nearby locations, such as Lord Howe Island, and offset by a month or two with tropical populations of this species. Gametogenetic cycles were longer than those of species with similar-sized gametes in the tropics, suggesting that environmental variables, such as temperature and light, have a strong influence on the length of the gametogenetic cycle. 
Acknowledgements. Permission to permanently tag colonies was given by the DOPI (permit P11/0041-1.0). We thank M. Diaz, J. Martinelli, M. Kosnik and O. Luiz for their help on field trips. This project was assisted by the New South Wales Government through its Environmental Trust and by the Australia Research Council through funds provided to A.H.B. via the ARC Centre of Excellence for Coral Reef Studies.

\section{LITERATURE CITED}

Baird AH, Marshall PA, Wolstenholme J (2002) Latitudinal variation in the reproduction of Acropora in the Coral Sea. Proc 9th Int Coral Reef Symp 1:385-389

Baird AH, Cumbo VR, Leggat W, Rodriguez-Lanetty M (2007) Fidelity and flexibility in coral symbioses. Mar Ecol Prog Ser 347:307-309

Baird AH, Birrell CL, Hughes TP, McDonald A and others (2009a) Latitudinal variation in reproductive synchrony in Acropora assemblages: Japan vs. Australia. Galaxea 11:101-108

Baird AH, Guest JR, Willis BL (2009b) Systematic and biogeographical patterns in the reproductive biology of scleractinian corals. Annu Rev Ecol Evol Syst 40:551-571

Baird AH, Blakeway DR, Hurley TJ, Stoddart JA (2011) Seasonality of coral reproduction in the Dampier Archipelago, northern Western Australia. Mar Biol 158:275-285

Bauman AG, Baird AH, Cavalcante GH (2011) Coral reproduction in the world's warmest reefs: southern Persian Gulf (Dubai, United Arab Emirates). Coral Reefs 30: 405-413

Benzoni F, Arrigoni R, Stefani F, Pichon M (2011) Phylogeny of the coral genus Plesiastrea (Cnidaria, Scleractinia). Contrib Zool 80:231-249

> Cairns SD (1999) Species richness of recent Scleractina. Atoll Res Bull 459:1-46

Crossins AR, Bowler KB (1987) Temperature biology. Chapman \& Hall, London

> Cumbo VR, Baird AH, Oppen MJH (2013) The promiscuous larvae: flexibility in the establishment of symbiosis in corals. Coral Reefs 32:111-120

Dai CF, Soong K, Fan TY (1992) Sexual reproduction of corals in northern and southern Taiwan. Proc 7th Int Coral Reef Symp 1:448-455

Fellegara I, Baird AH, Ward S (2013) Coral reproduction in a high-latitude, marginal reef environment (Moreton Bay, south-east Queensland, Australia). Invertebr Reprod Dev 57:219-223

> Goffredo S, Airi V, Radetic J, Zaccanti F (2006) Sexual reproduction of the solitary sunset cup coral Leptopsammia pruvoti (Scleractinia, Dendrophylliidae) in the Mediterranean. 2. Quantitative aspects of the annual reproductive cycle. Mar Biol 148:923-931

Hall VR, Hughes TP (1996) Reproductive strategies of modular organisms: comparative studies of reef-building corals. Ecology 77:950-963

Harii S, Omori M, Yamakawa H, Koike Y (2001) Sexual reproduction and larval settlement of the zooxanthellate coral Alveopora japonica Eguchi at high latitudes. Coral Reefs 20:19-23

Harriott VJ, Banks SA (2002) Latitudinal variation in coral communities in eastern Australia: a qualitative biophysical model of factors regulating coral reefs. Coral Reefs 21:83-94

> Harriott VJ, Smith SDA, Harrison PL (1994) Patterns of coral community structure of subtropical reefs in the Solitary
Islands Marine Reserve, Eastern Australia. Mar Ecol Prog Ser 109:67-76

Harrison PL (1985) Sexual characteristics of scleractinian corals: systematic and evolutionary implications. Proc 5th Int Coral Reef Congr 4:337-342

Harrison PL (2008) Coral spawn slicks at Lord Howe Island, Tasman Sea, Australia; the world's most southerly coral reef. Coral Reefs 27:35

Harrison PL (2011) Sexual reproduction of scleractinian corals. In: Dubinsky Z, Stambler N (eds) Coral reefs: an ecosystem in transition. Springer Science, Berlin, p 59-85

Harrison PL, Wallace CC (1990) Reproduction, dispersal and recruitment of scleractinian corals. In: Dubinsky Z (ed) Coral reefs, Vol 25. Elsevier, Amsterdam, p 133-207

> Harrison PL, Babcock RC, Bull GD, Oliver JK, Wallace CC, Willis BL (1984) Mass spawning in tropical reef corals. Science 223:1186-1189

Huang D (2012) Threatened reef corals of the world. PLoS ONE 7:e34459

Kerr AM, Baird AH, Hughes TP (2011) Correlated evolution of sex and reproductive mode in corals (Anthozoa: Scleractinia). Proc R Soc B Biol Sci 278:75-81

Kleypas JA, McManus JW, Menez LAB (1999) Environmental limits to coral reef development: Where do we draw the line? Am Zool 39:146-159

Loya Y, Sakai K (2008) Bidirectional sex change in mushroom stony corals. Proc R Soc B Biol Sci 275:2335-2343

> Nozawa Y, Tokeshi M, Nojima S (2006) Reproduction and recruitment of scleractinian corals in a high-latitude coral community, Amakusa, southwestern Japan. Mar Biol 149:1047-1058

Richmond RH (1987) Energetics, competency, and long-distance dispersal of planula larvae of the coral Pocillopora damicornis. Mar Biol 93:527-533

Rodriguez-Lanetty M, Hoegh-Guldberg O (2002) The phylogeography and connectivity of the latitudinally widespread scleractinian coral in the Western Pacific. Mol Ecol 11:1177-1189

Rodriguez-Lanetty M, Loh W, Carter D, Hoegh-Guldberg O (2001) Latitudinal variability in symbiont specificity within the widespread scleractinian coral Plesiastrea versipora. Mar Biol 138:1175-1181

van Woesik R (1995) Coral communities at high latitude are not pseudopopulations: evidence of spawning at $32^{\circ} \mathrm{N}$, Japan. Coral Reefs 14:119-120

van Woesik R, Lacharmoise F, Koksal S (2006) Annual cycles of solar insolation predict spawning times of Caribbean corals. Ecol Lett 9:390-398

Vargas-Ángel B, Colley SB, Hoke SM, Thomas JD (2006) The reproductive seasonality and gametogenic cycle of Acropora cervicornis off Broward County, Florida, USA. Coral Reefs 25:110-122

Veron JEN (1993) A biogeographic database of hermatypic corals, Vol 10. Australian Institute of Marine Science, Townsville

Veron JEN (2000) Corals of the world. AIMS, Townsville

> Veron JEN, Done TJ (1979) Corals and coral communities of Lord Howe Island. Aust J Mar Freshw Res 30:203-236

Willis BL, Babcock RC, Harrison PL, Oliver JK (1985) Patterns in the mass spawning of corals on the Great Barrier Reef from 1981 to 1984 . Proc 5th Int Coral Reef Symp 4: 343-348

Wilson JR, Harrison PL (2003) Spawning patterns of scleractinian corals at the Solitary Islands - a high latitude coral community in eastern Australia. Mar Ecol Prog Ser 260: $115-123$ 